\title{
Editorial: Connecting Mountain Hydroclimate Through the American Cordilleras
}

\author{
Alfonso Fernández ${ }^{1 *}$, Bryan G. Mark ${ }^{2}$ and Michel Baraer ${ }^{3}$ \\ ${ }^{1}$ Department of Geography, Mountain Geoscience Group, Universidad de Concepción, Concepción, Chile, ${ }^{2}$ Department of \\ Geography, The Ohio State University, Columbus, $\mathrm{OH}$, United States, ${ }^{3} \mathrm{Hydrology}$, Climate and Climate Change Laboratory, \\ École de Technologie Supérieure, Montréal, QC, Canada
}

Keywords: hydroclimate, mountain environments, climate change, cryosphere, hydrology, climate modeling, meteorological observations and measurements

\section{Editorial on the Research Topic}

\section{Connecting Mountain Hydroclimate Through the American Cordilleras}

Mountains are key hydroclimatic features that couple large-scale atmospheric processes with the earth surface, influencing the development of diverse waterscapes. Decades of transformative research have highlighted how mountains are valuable for society, revealing that changes in these landscapes exert significant impacts on downstream hydrological regimes that support lives and livelihoods of millions (Viviroli et al., 2020). Yet despite sharing common features of verticality and orographic uplift, the complexity of mountain environments is an inherent feature that inevitably leads to geographic particularities, and challenges maintaining consistent observations. Nowadays, many of these mountain waterscapes are undergoing significant alterations in the context of ongoing climate and environmental changes (Immerzeel et al.,

\section{OPEN ACCESS}

Edited and reviewed by: Nick Van De Giesen, Delft University of Technology, Netherlands

*Correspondence: Alfonso Fernández alfernandez@udec.cl

Specialty section: This article was submitted to Biophysics,

a section of the journal Frontiers in Earth Science

Received: 12 February 2021 Accepted: 18 February 2021

Published: 23 March 2021

Citation: Fernández A, Mark BG and Baraer M (2021) Editorial: Connecting Mountain Hydroclimate Through the American Cordilleras. Front. Earth Sci. 9:667264. doi: 10.3389/feart.2021.667264
2020). The vast latitudinal expanse of the Cordilleras that span from Patagonia to Alaska provides abundant examples of mountain hydroclimatic dynamics as they traverse entire atmospheric systems and delimit diverse climatic regions. Along this interhemispheric transect are similarities and contrasts in both biophysical and human components, whereby intercomparisons may broaden understanding. How similar and how distinct is the research emerging in this context? Can we, as a community of researchers, leverage our geographic diversity to gain new insights that so far have not been described in a frame facilitating cross comparisons along the American Cordilleras? The present collection of research papers aims to move us forward to questioning our perspectives and advance coordinated efforts, with studies highlighting different aspects of the hydroclimate along the American mountains. Our intention with this special edition is to show diverse research — distinct in methodology, scale, and topic - that is linked to a common mountain hydroclimatic theme. The context of rapid climate and environmental change raises the value and urgency of mountain research that allows for comparative views along the American Cordilleras, and we anticipate that such efforts might elucidate constructive perspectives into changes taking place at unprecedented rates, and ideally may support future strategies to tackle these emergent challenges.

Instrumental and satellite observations are vital tools for accurate hydroclimatic characterization. For mountain areas, acquiring, curating and organizing data remain challenging and thus systematization efforts need to be encouraged. Condom et al. have likely produced one of the most exhaustive analysis of available hydroclimatic datasets from the Andes. The study shows that in almost all countries actual instrumental records comprise a small percentage of national networks. They suggest that satellite data may become a crucial source for hydroclimatic analysis given the increasing coverage over the region, albeit with diverse spatiotemporal resolutions that necessitate 
further evaluations of these data. Sambuco et al. demonstrate that a relatively dense network of well-distributed embedded sensors recording continuous observations of a few variables in the Great Basin National Park, United States, reveal spatiotemporal patterns that may provide effective alternatives to more expensive single stations. They may allow for more accurate evaluation of water resources on mountains since they span over $2 \mathrm{~km}$ vertical range to record seasonal changes in lapse rates, document significant temperature changes in diverse microenvironments, and thus capture the influence of site characteristics on sensor's records. Under the scenario of notorious gaps of observations along the American Cordilleras, numerical modeling offers a viable alternative to develop process-based understanding of atmosphere-hydrosphere linkages within high elevation environments. Sarmiento and Kooperman provide a muchneeded transdisciplinary perspective on the impacts of expected precipitation increases along the Tropical Andes derived from the Coupled Model Intercomparison Model Project phase five (CMIP5). In Ecuador, Campozano et al. combined instrumental observations, CMIP5 model output and dynamical downscaling to assess future scenarios of drought. They demonstrate that present day conditions are well reproduced by models within high elevation regions in this country, while projections point to lower probability of droughts.

Since global climate models are too coarse in resolution to adequately represent detailed processes within American mountain regions given their narrow zonal extension, limited area models and dynamical downscaling methods become relevant tools. By providing continuous climate fields/grids at finer-scales, such modeling studies may improve interpretations derived from observational networks and provide targeted projections for hydroclimatic planning. Wrzesien and Pavelsky used the Weather Research and Forecasting model (WRF) to downscale CMIP5 output, studying precipitation and runoff changes in the Western United States. They project that, in several mountainous catchments draining mountain areas, the timing of peak discharge changes and extreme runoff increases in the future. Along the same lines, Schumacher et al. downscaled the ERA-Interim reanalysis at different cell sizes over a $\sim 500 \mathrm{~km}$ Andean strip between $32^{\circ}$ and $38^{\circ} \mathrm{S}$, and analyzed the performance of the WRF model to reproduce precipitation observational datasets, detecting that the modeling captured seasonal and interannual variability. They suggest that a better resolved topography improves model performance according to elevation. Over the same Andean region, Alvial Vásquez et al. developed a gridded precipitation dataset for hydroclimatic studies using a combination of WRF downscaling at $4 \mathrm{~km}$ and a multilinear regression model based on topography and locational descriptors. They deliver a final product at about $800 \mathrm{~m}$ grid cell resolution that describes the conditions in the study area well.

Complex interactions between topography and atmospheric systems determine features that need to be considered in the interpretation of changes in mountain hydroclimate. The tandem contributions of Arias et al. and Espinoza et al. deliver detailed characterizations of the climate and hydrology of the Andes from the tropics to Patagonia. This description was made by focusing on large-scale atmospheric dynamics and continental water balance, and in the process they propose open research questions. Pabón-Caicedo et al.'s review changes in Andean runoff, precipitation, and temperature, providing the most up-to-date synthesis of trends emerging within the region while featuring some of the latest scenario projections based upon climatic downscaling. These large-scale analyses are often used for developing case-studies that better support decision-making on mountain water resources. Fernández-Alberti et al. use hydrological modeling to assess water resources within mountain basins featuring diverse land uses, such as in the Andes of southern Chile, by computing a water balance and carefully considering supplies and demands. Two papers focus on characterization of particular atmospheric interactions: Poveda et al. provide a detailed overview of the consequences of extreme weather events along the Andes, highlighting the distinct mesoscale atmospheric systems that produce damaging events such as flash floods and cold waves. Saavedra et al. reveal that atmospheric rivers in the Andes between $26.5^{\circ}$ and $36.5^{\circ} \mathrm{S}$ and the different phases of El Niño Southern Oscillation impact the number and intensity of snowfall events.

One of the most definitive features of the American Cordilleras running along the west edge of the continent is the glacier and perennial snow coverage. Thus, monitoring the cryosphere in this region is a fundamental requisite for hydroclimatic understanding. The different papers that focus on glaciers in this Frontiers' topic picture a generalized shrinking punctuated by short periods of slowing down of the general trends. Masiokas et al. review the latest literature on the Andean cryosphere, highlighting unprecedented advances in remotely sensed glacier monitoring during the last two decades afforded by the availability of imagery while stressing the need for continuous in-situ monitoring and further research on glacier-melt contribution to runoff. Kinnard et al. present a study over a cold-glacier in the Chilean Andes, analyzing a rich pool of data on volumetric fluctuations, glacier geochemistry, and climate, which facilitate a much needed process-based understanding and mass balance reconstruction for this particular region. In the Northern Hemisphere, Doumbia et al. quantified ice loss over the Gulf of Alaska by downscaling data from the Gravity Recovery And Climate Experiment (GRACE), providing a new estimate for this region as well as a downscaling method that may be applied in other regions with large glacier coverage. Finally, Moore et al. point to the increasingly concerning issue of hydrological thresholds in glacierized catchments, in this case exemplified in a section of the Columbia river basin where they find that late summer streamflow reveals the consequences of glacier shrinkage over the last four decades.

We assert that this collection of papers provides a compendium exemplifying current research underway all along the American Cordillera that documents the hydroclimatic diversity and vulnerability within mountain environments. We think that the variety of studies and 
reviews presented attest to a healthy scientific community that is progressing in novel directions that could be incorporated to support more coordinated efforts and better management decisions under future hydroclimatic scenarios.

\section{AUTHOR CONTRIBUTIONS}

AF wrote the first draft of the manuscript. All authors contributed to manuscript revision, read, and approved the submitted version.

\section{REFERENCES}

Immerzeel, W. W., Lutz, A. F., Andrade, M., Bahl, A., Biemans, H., Bolch, T., et al. (2020). Importance and vulnerability of the world's water towers. Nature 577, 364-369. doi:10.1038/s41586-019-1822-y

Viviroli, D., Kummu, M., Meybeck, M., Kallio, M., and Wada, Y. (2020). Increasing dependence of lowland populations on mountain water resources. Nat. Sustain. 3, 917. doi:10.1038/s41893020-0559-9

\section{FUNDING}

AF is funded by the Chilean Science Council (ANID) FONDECYT 1201429. MB is funded by the Natural Science and Engineering Research Council (NSERC) of Canada RGPNS-2020-05612.

\section{ACKNOWLEDGMENTS}

BM acknowledges funding from the Western National Parks Association and the Department of Geography at The Ohio State University.

Conflict of Interest: The authors declare that the research was conducted in the absence of any commercial or financial relationships that could be construed as a potential conflict of interest.

Copyright (c) 2021 Fernández, Mark and Baraer. This is an open-access article distributed under the terms of the Creative Commons Attribution License (CC BY). The use, distribution or reproduction in other forums is permitted, provided the original author(s) and the copyright owner(s) are credited and that the original publication in this journal is cited, in accordance with accepted academic practice. No use, distribution or reproduction is permitted which does not comply with these terms. 